\title{
A Survey on Efficiency and Profitable Trading Opportunities in Cryptocurrency Markets
}

\author{
Nikolaos A. Kyriazis \\ Laboratory of Economic Policy and Strategic Planning, Department of Economics, University of Thessaly, \\ 28th October 78 Street, P.C. 38333 Volos, Greece; knikolaos@uth.gr
}

Received: 2 April 2019; Accepted: 15 April 2019; Published: 18 April 2019

check for updates

\begin{abstract}
This study conducts a systematic survey on whether the pricing behavior of cryptocurrencies is predictable. Thus, the Efficient Market Hypothesis is rejected and speculation is feasible via trading. We center interest on the Rescaled Range (R/S) and Detrended Fluctuation Analysis (DFA) as well as other relevant methodologies of testing long memory in returns and volatility. It is found that the majority of academic papers provides evidence for inefficiency of Bitcoin and other digital currencies of primary importance. Nevertheless, large steps towards efficiency in cryptocurrencies have been traced during the last years. This can lead to less profitable trading strategies for speculators.
\end{abstract}

Keywords: survey; bitcoin; cryptocurrency; efficient market hypothesis

JEL Classification: G11; G12; G15; E4

\section{Introduction}

Since its introduction by Nakamoto (2008), the exponential growth of Bitcoin and other digital currencies has aroused sparkling interest concerning governments, academics, investors, traders and portfolio managers. This very new type of money carries characteristics both of commodity and money (Selgin 2015; Ammous 2018) and is tagged with the all-encompassing label of "cryptocurrency". Bitcoin, the most popular among cryptocurrencies, has aroused a proliferating bulk of academic work studying its returns and volatility characteristics, such as in Dyhrberg (2016a, 2016b), Fry and Cheah (2016), Katsiampa (2017), Urquhart (2016, 2017), Corbet et al. (2018, 2019), Bouri et al. (2017a, 2017b), Baur et al. (2018a, 2018b) and Beneki et al. (2019). One of the fundamental aspects of digital currencies that has attracted increasing attention is whether such markets are consistent with the Efficient Markets Hypothesis (EMH).

One of the most radical perspectives of modelling financial data are the three forms of the Efficient Markets Hypothesis, as has been expressed by Fama (1970), in order to detect the existence of any predictable patterns that could form the basis for profitable trading strategies. The Efficient Market Hypothesis constitutes the cornerstone of financial economics and is based on the seminal work of Bachelier in the early 20th century and Fama (1970). Fama defines informational efficiency in a market as the status when "prices reflect full information" in this market.

These are the main forms of informational efficiency most commonly expressed. Firstly, weak-form efficiency in quotes of assets depict all the information inhibited in past prices of these assets. Secondly, semi-strong efficiency stands for present prices reflecting all information easily accessible to public. Thirdly, strong-form efficiency represents the situation where quotes nowadays reflect all public and private information.

Among the three forms of the EMH, the most commonly employed is the weak-form EMH, which represents the inability of interested investors to take advantage of information about past quotes of investible assets in order to envision the future values of these assets. When the Efficient 
Markets Hypothesis is valid, there cannot be long memory in time series concerning financial assets. Therefore, no abnormal returns can be achieved by investors should they try to follow a profitable investing strategy with minimum risk. Differently said, speculation based on long-range dependence in returns is not applicable when EMH holds.

To the best of our knowledge, no study until now has investigated the full spectrum of academic literature on profitable trading based on cryptocurrencies. Differently said, the present study is the first one to conduct a thorough and integrated review of the existing empirical work on whether cryptocurrency markets can outperform the market, thereby leading to abnormal profit-making by investors. A small but upcoming number of important papers such as Urquhart (2016), Nadarajah and Chu (2017) and Bariviera (2017) have paved the way for a more mature viewpoint in the efficiency of digital coin markets.

The remainder of this paper is structured as follows. Section 2 lays out the studies about efficiency in Bitcoin markets. Section 3 provides an overview of the nascent but already very informative domain of Efficient Market Hypothesis testing in a broader spectrum of cryptocurrencies. In Section 4, the conclusions are discussed.

\section{Studies about Efficiency in Bitcoin Markets}

An important number of academic papers have investigated long-range dependence and whether this could co-exist with the Efficient Market Hypothesis. A battery of tests have been employed in order to measure whether weak-form efficiency in the Bitcoin market is valid. Empirical findings by the great majority of papers about Bitcoin provide evidence of inefficiency, thereby profitable trading opportunities. It should be emphasized though that the capacity to outperform the market by investing in Bitcoin fades out as the Bitcoin market renders more mature. Table 1 provides the prestigious studies with examination of the Efficient Market Hypothesis in cryptocurrency markets that have been conducted so far, the relevant data sources as well as the methodologies adopted and whether they detect inefficiency or not.

Table 1. Studies about EMH in cryptocurrency markets with data sources, methodology and conclusions about level of inefficiency.

\begin{tabular}{|c|c|c|c|}
\hline Study & Data Source & Methodology & Efficiency or Not \\
\hline Aggarwal (2019) & www.coindesk.com & $\begin{array}{c}\text { Augmented Dickey-Fuller test based on } \\
\text { Dickey and Fuller (1979) } \\
\text { Phillips-Perron test in Phillips (1987) } \\
\text { Kwiatkowski et al. (1992) test } \\
\text { Zivot and Andrews (2002) structural } \\
\text { breakpoint test } \\
\text { Lo and MacKinlay (1988) multiple variance } \\
\text { ratio (MVR) test } \\
\text { BDS test by Brock et al. (1996) } \\
\text { ARCH by Engle (1982) } \\
\text { GARCH by Bollerslev (1986) } \\
\text { E-GARCH by Nelson (1991) } \\
\text { TARCH by Zakoian (1994) }\end{array}$ & Inefficiency \\
\hline Almudhaf (2018) & $\begin{array}{l}\text { http://grayscale.co/ } \\
\text { bitcoin-investment- } \\
\text { trust }\end{array}$ & OLS with Newey-West's covariance estimator & Inefficiency \\
\hline $\begin{array}{l}\text { Alvarez-Ramirez et } \\
\text { al. (2018) }\end{array}$ & www.coindesk.com & $\begin{array}{l}\text { Detrended Fluctuation Analysis (DFA) } \\
\text { Scaling Exponent over Sliding Window } \\
\text { Asymmetric Scaling Exponent }\end{array}$ & Inefficiency \\
\hline $\begin{array}{l}\text { Al-Yahyaee et al. } \\
\qquad(2018)\end{array}$ & $\begin{array}{c}\text { Datastream } \\
\text { Coindesk Price Index } \\
\text { website }\end{array}$ & $\begin{array}{l}\text { Multifractal Detrended Fluctuation Analysis } \\
\text { (MF-DFA) }\end{array}$ & Inefficiency \\
\hline
\end{tabular}


Table 1. Cont.

\begin{tabular}{|c|c|c|c|}
\hline Study & Data Source & Methodology & Efficiency or Not \\
\hline Bariviera (2017) & Datastream & $\begin{array}{c}\text { Hurst (1951) exponent } \\
\text { Detrended Fluctuation Analysis (DFA) }\end{array}$ & $\begin{array}{l}\text { Inefficiency but } \\
\text { decreasing }\end{array}$ \\
\hline $\begin{array}{l}\text { Bariviera et al. } \\
\quad(2017)\end{array}$ & Datastream & $\begin{array}{l}\text { Hurst (1951) exponent } \\
\text { Detrended Fluctuation Analysis (DFA) }\end{array}$ & $\begin{array}{l}\text { Inefficiency/ } \\
\text { Efficiency }\end{array}$ \\
\hline Bouri et al. (2019) & $\begin{array}{c}\text { Bitstamp } \\
\text { Coindesk Price Index } \\
\text { website }\end{array}$ & $\begin{array}{c}\text { ARIMA (parametric, semiparametric d } \\
\text { estimations) } \\
\text { Bai and Perron (2003) structural break tests }\end{array}$ & Inefficiency \\
\hline Bouri et al. (2018) & $\begin{array}{l}\text { www.coinmarketcap. } \\
\text { com }\end{array}$ & $\begin{array}{l}\text { Copula-Granger Causality in Distribution } \\
\text { (CGCD) by Lee and Yang (2014) }\end{array}$ & Inefficiency \\
\hline $\begin{array}{l}\text { Brauneis and } \\
\text { Mestel (2018) }\end{array}$ & Coinmarketcap.com & $\begin{array}{c}\text { Ljung and Box (1978) test } \\
\text { Wald and Wolfowitz (1940) runs-test } \\
\text { Variance ratio test by Lo and MacKinlay } \\
\text { (1988) } \\
\text { Kim (2009) wild bootstrap automatic variance } \\
\text { ratio test based on Chow and Denning (1993) } \\
\text { Bartels (1982) test } \\
\text { Hurst (1951) exponent }\end{array}$ & $\begin{array}{l}\text { Higher efficiency in } \\
\text { Bitcoin }\end{array}$ \\
\hline $\begin{array}{l}\text { Caporale et al. } \\
\text { (2018) }\end{array}$ & Coinmarketcap.com & $\begin{array}{c}\mathrm{R} / \mathrm{S} \text { analysis } \\
\text { Fractional integration }\end{array}$ & Inefficiency \\
\hline $\begin{array}{l}\text { Chaim and Laurini } \\
\text { (2018) }\end{array}$ & $\begin{array}{l}\text { Coinmetrics.io } \\
\text { FRED database }\end{array}$ & Laurini et al. (2016) model & Inefficiency \\
\hline $\begin{array}{l}\text { Chaim and Laurini } \\
\text { (2019) }\end{array}$ & Coinmetrics.io & Laurini et al. (2016) model & Inefficiency \\
\hline $\begin{array}{l}\text { Charfeddine and } \\
\text { Maouchi (2018) }\end{array}$ & Coinmarketcap.com & $\begin{array}{c}\text { Geweke and Porter-Hudak (1983) (GHP) test } \\
\text { Gaussian semi parametric (GSP) test of } \\
\text { Robinson (1995a) } \\
\text { Local Whittle (LW) of Robinson (1995b) } \\
\text { Exact Local Whittle (ELW) of Shimotsu and } \\
\text { Phillips (2005) } \\
\text { R/S test of Lo (1991) } \\
\text { Rescaled Variance (V/S) test of Giraitis et al. } \\
\text { (2003) }\end{array}$ & $\begin{array}{c}\text { Inefficiency, } \\
\text { Efficiency (ETH) }\end{array}$ \\
\hline Cheah et al. (2018) & $\begin{array}{l}\text { www.bitcoincharts. } \\
\text { com }\end{array}$ & FCVAR by Johansen and Nielsen (2012) & Inefficiency \\
\hline $\begin{array}{l}\text { El Alaoui et al. } \\
\qquad(2018)\end{array}$ & $\begin{array}{l}\text { www. } \\
\text { cryptocompare.com }\end{array}$ & $\begin{array}{l}\text { Multifractal Detrended Cross-correlations } \\
\text { Analysis (MF-DCCA) by Zhou (2008) }\end{array}$ & Inefficiency \\
\hline $\begin{array}{l}\text { Hattori and Ishida } \\
\text { (2019) }\end{array}$ & Bloomberg & Regression & Inefficiency \\
\hline Ji et al. (2018) & www.coindesk.com & $\begin{array}{c}\text { Directed Acyclical Graph (DAG) by Spirtes et } \\
\text { al. (2000) } \\
\text { Vector Autoregression (VAR) } \\
\text { Error Correction Model (ECM) } \\
\text { Forecast Error Variance Decomposition } \\
\text { (FEVD) }\end{array}$ & $\begin{array}{l}\text { Very weak } \\
\text { inefficiency }\end{array}$ \\
\hline Jiang et al. (2018) & $\begin{array}{l}\text { www.bitcoinaverage. } \\
\text { com }\end{array}$ & $\begin{array}{c}\text { Hurst (1951) exponent and rolling windows } \\
\text { Ljung -Box test } \\
\text { AVR test }\end{array}$ & Inefficiency \\
\hline Kaiser (2018) & Coinmarketcap.com & $\begin{array}{l}\text { Bid-ask spread estimation as by Abdi and } \\
\text { Ranaldo (2017) } \\
\text { Volatility estimation as by Rogers and } \\
\text { Satchell (1991) } \\
\text { GARCH by Bollerslev (1986) }\end{array}$ & Efficiency \\
\hline $\begin{array}{c}\text { Khuntia and } \\
\text { Pattanayak (2018) }\end{array}$ & www.coindesk.com & $\begin{array}{l}\text { Dominguez- Lobato (DL) test } \\
\text { Generalized Spectral (GS) test }\end{array}$ & $\begin{array}{l}\text { Efficiency } \\
\text { evolving-(Adaptive } \\
\text { Market) }\end{array}$ \\
\hline
\end{tabular}


Table 1. Cont.

\begin{tabular}{|c|c|c|c|}
\hline Study & Data Source & Methodology & Efficiency or Not \\
\hline $\begin{array}{l}\text { Köchling et al. } \\
\text { (2018) }\end{array}$ & $\begin{array}{l}\text { www.bitcoinaverage. } \\
\text { com }\end{array}$ & $\begin{array}{c}\text { Ljung and Box (1978) test } \\
\text { Escanciano and Lobato (2009) automatic } \\
\text { portmanteau test } \\
\text { Wald and Wolfowitz (1940) runs-test } \\
\text { Bartels (1982) } \\
\text { Durlauf (1991) spectral shape test } \\
\text { Escanciano and Velasco (2006) generalized } \\
\text { spectral test } \\
\text { Kim (2009) wild bootstrap automatic variance } \\
\text { ratio test } \\
\text { Brock et al. (1996) BDS test } \\
\text { Hurst (1951) exponent }\end{array}$ & $\begin{array}{l}\text { Inefficiency but } \\
\text { decreasing }\end{array}$ \\
\hline $\begin{array}{l}\text { Köchling et al. } \\
\text { (2019) }\end{array}$ & Coimarketcap.com & $\begin{array}{l}3 \text { delay measures by Hou and Moskowitz } \\
\text { (2005) }\end{array}$ & $\begin{array}{l}\text { Inefficiency but } \\
\text { decreasing }\end{array}$ \\
\hline Kristoufek (2018) & www.coindesk.com & $\begin{array}{l}\text { Efficiency Index of Kristoufek and Vosvrda } \\
\qquad \text { (2013) }\end{array}$ & $\begin{array}{l}\text { Inefficiency } \\
\text { Efficiency only } \\
\text { after cooling down } \\
\text { of bubbles }\end{array}$ \\
\hline $\begin{array}{c}\text { Kurihara and } \\
\text { Fukushima (2017) }\end{array}$ & $\begin{array}{l}\text { www.bitcoinaverage. } \\
\text { com }\end{array}$ & $\begin{array}{l}\text { Ordinary Least Squares (OLS) } \\
\text { Robust Least Squares (RLS) }\end{array}$ & Inefficiency \\
\hline $\begin{array}{l}\text { Lahmiri and } \\
\text { Bekiros (2018) }\end{array}$ & www.coindesk.com & $\begin{array}{c}\text { Largest Lyapunov Exponent (LLE) } \\
\text { Shannon entropy (SE) } \\
\text { Multi-fractal Detrended Fluctuation Analysis } \\
\text { (MF-DFA) }\end{array}$ & Inefficiency \\
\hline $\begin{array}{l}\text { Lahmiri et al. } \\
\qquad(2018)\end{array}$ & data.Bitcoinity.org & $\begin{array}{c}\text { Fractionally integrated GARCH (FIGARCH) } \\
\text { by Baillie et al. (1996) } \\
\text { Shannon entropy by Shannon (1948) }\end{array}$ & Inefficiency \\
\hline Mbanga (2018) & $\begin{array}{l}\text { www.bitcoincharts. } \\
\text { com }\end{array}$ & Huber (1964) M estimations & Inefficiency \\
\hline $\begin{array}{l}\text { Nadarajah and Chu } \\
\qquad(2017)\end{array}$ & $\begin{array}{l}\text { www.bitcoinaverage. } \\
\text { com }\end{array}$ & $\begin{array}{c}\text { Ljung and Box (1978) test } \\
\text { Runs test by Wald and Wald and Wolfowitz } \\
\text { (1940) } \\
\text { Bartels (1982) test } \\
\text { Wild-bootstrapped AVR test by Kim (2009) } \\
\text { Spectral shape tests by Durlauf (1991) and } \\
\text { Choi (1999) } \\
\text { BDS test by Brock et al. (1996) } \\
\text { Portmanteau test by Escanciano and Lobato } \\
\text { (2009) } \\
\text { Generalized spectral test by Escanciano and } \\
\text { Velasco (2006) }\end{array}$ & Inefficiency \\
\hline Phillip et al. (2018a) & $\begin{array}{l}\text { Brave New Coin } \\
\text { (BNC) Digital } \\
\text { Currency indices }\end{array}$ & $\begin{array}{l}\text { Ljung and Box (1978) test } \\
\text { Kolmogorov-Smirnov test by Massey (1951) } \\
\text { Generalized long-term memory by Gray et al. } \\
\text { (1989) } \\
\text { Generalized long memory (GLM)- stochastic } \\
\text { volatility (SV)- leverage (LVG) and heavy } \\
\text { tails (HT) model }\end{array}$ & Inefficiency \\
\hline $\begin{array}{l}\text { Phillip et al. } \\
\text { (2018b) }\end{array}$ & $\begin{array}{l}\text { Brave New Coin } \\
\text { (BNC) Digital } \\
\text { Currency indices }\end{array}$ & $\begin{array}{l}\text { Jump BAR SV Gegenbauer Log Range } \\
\text { (JBAR-SV-GLR) model, as combination of } \\
\text { Zhu et al. (2014) and Taylor (2007) }\end{array}$ & Inefficiency \\
\hline Sensoy (2018) & 64 Bitcoin exchanges & $\begin{array}{c}\text { Matilla-García and Marín (2008) } \\
\text { López et al. (2010) }\end{array}$ & $\begin{array}{l}\text { Inefficiency } \\
\text { More efficient since } \\
2016\end{array}$ \\
\hline $\begin{array}{l}\text { Takaishi and } \\
\text { Adachi (2018) }\end{array}$ & $\begin{array}{l}\text { www.coindesk.com } \\
\text { Histdata.com }\end{array}$ & Autocorrelation tests & Inefficiency \\
\hline
\end{tabular}


Table 1. Cont.

\begin{tabular}{|c|c|c|c|}
\hline Study & Data Source & Methodology & Efficiency or Not \\
\hline Tiwari et al. (2018) & www.coindesk.com & $\begin{array}{c}\text { Hurst (1951) exponent } \\
\text { DFA } \\
\text { CMA-1 and CMA-2 by Bashan et al. (2008) } \\
\text { Periodogram-LAD and Periodogram-LS by } \\
\text { Taqqu et al. (1995) } \\
\text { GPH by Geweke and Porter-Hudak (1983) } \\
\text { MLE estimators by Haslett and Raftery (1989) }\end{array}$ & Inefficiency \\
\hline Urquhart (2016) & $\begin{array}{l}\text { www.bitcoinaverage. } \\
\text { com }\end{array}$ & $\begin{array}{c}\text { Ljung and Box (1978) test } \\
\text { Runs test by Wald and Wolfowitz (1940) } \\
\text { Automatic variance test (AVR) } \\
\text { Wild-bootstrapped AVR test by Kim (2009) } \\
\text { BDS test by Brock et al. (1996) } \\
\text { Hurst (1951) exponent }\end{array}$ & Inefficiency \\
\hline Urquhart (2017) & $\begin{array}{l}\text { www.bitcoincharts. } \\
\text { com }\end{array}$ & $\begin{array}{l}\text { Clustering test } \\
\text { Probit model }\end{array}$ & Inefficiency \\
\hline $\begin{array}{l}\text { Vidal-Tomás and } \\
\text { Ibañez (2018) }\end{array}$ & Bitstamp and Mt.Gox & CGARCH, AR-CGARCH-M & $\begin{array}{l}\text { Inefficiency but } \\
\text { decreasing }\end{array}$ \\
\hline Wei (2018) & $\begin{array}{l}\text { www.coinmarketcap. } \\
\text { com }\end{array}$ & $\begin{array}{c}\text { Ljung and Box (1978) test } \\
\text { Runs test by Wald and Wolfowitz (1940) } \\
\text { Bartels test } \\
\text { Automatic variance test (AVR) } \\
\text { Wild-bootstrapped AVR test by Kim (2009) } \\
\text { BDS test by Brock et al. (1996) } \\
\text { Hurst (1951) exponent } \\
\text { Amihud (2002) illiquidity ratio }\end{array}$ & Inefficiency \\
\hline $\begin{array}{l}\text { Zargar and Kumar } \\
\text { (2019a) }\end{array}$ & Bloomberg & $\begin{array}{c}\text { Variance ratio (VR) test by Lo and MacKinlay } \\
\text { (1988) } \\
\text { Multiple Variance Ratio (MVR) test by Chow } \\
\text { and Denning (1993) } \\
\text { Automatic Variance Ratio (AVR) test by Choi } \\
\text { (1999) } \\
\text { Joint Variance Ratio (JVR) test by Chen and } \\
\text { Deo (2006) } \\
\text { Kuan and Lee (2004) (KL) test }\end{array}$ & $\begin{array}{l}\text { Inefficiency at } \\
\text { higher data } \\
\text { frequencies }\end{array}$ \\
\hline $\begin{array}{l}\text { (Zargar and Kumar } \\
(2019 b)\end{array}$ & Bloomberg & $\begin{array}{c}\text { Local Whittle (LW) estimator } \\
\text { Exact Local Whittle (ELW) estimator } \\
\text { ARFIMA }\end{array}$ & Inefficiency \\
\hline Zhang et al. (2018) & Coinmarketcap.com & $\begin{array}{c}\text { Autocorrelation tests, GARCH by Bollerslev } \\
\text { (1986), GJR model by Glosten et al. (1993), } \\
\text { Detrended Fluctuation Analysis (DFA) by } \\
\text { Peng et al. (1995), Detrended Moving } \\
\text { Average Correlation Analysis (DMCA) by He } \\
\text { and Chen (2011) } \\
\text { Hurst (1951) exponent }\end{array}$ & Inefficiency \\
\hline
\end{tabular}

Among the initial important studies testing about efficiency in the Bitcoin market are Urquhart (2016, 2017), Nadarajah and Chu (2017) and Bariviera (2017). Urquhart (2016) adopted daily data in order to examine the informational efficiency of Bitcoin during the period from 1 August 2010 to 31 July 2016. He examined two nine-year subperiods with the end of July as 2013 separating them. The author employs a battery of tests such as the Ljung and Box (1978) test, the runs test (Wald and Wolfowitz 1940), the Bartels (1982) test, the variance ratio of Lo and Lo and MacKinlay (1988), the wild-bootstrapped test of Kim (2009), the BDS test of Brock et al. (1996) and the Hurst (1951) exponent for testing long memory. These tests reject randomness and the Hurst exponent advocates the existence of strong anti-persistence. Thereby, findings lead to the conclusion that no efficiency in Bitcoin market exists though there is a tendency towards a valid EMH since August 2013. Furthermore, 
Urquhart (2017) adopts data of various Bitcoin exchanges from 1 May 2012 to 30 April 2017 in order to investigate price clustering in Bitcoin markets. Evidence indicated that clustering takes place at round numbers as over one tenth of prices end with 00 decimals. Furthermore, there is weaker evidence of clustering around the 50 digit and the 99 digit. It was found that 1, 2, 3, 5 and 10 days before a round number from increasing prices returns indicate a positive sign, whereas afterwards returns are negative and not statistically significant. Overall, findings abide by the negotiation hypothesis of Harris (1991) because price clustering is linked to quotes and trading volume of Bitcoin.

In a similar perspective, Nadarajah and Chu (2017) employ data from 1 August 2010 to 31 July 2016 in order to study efficiency in the Bitcoin market. Furthermore, they divide the sample into two subperiods, the first one spanning from 1 August 2010 to 31 July 2013, and the second one covering 1 August 2013 to 31 July 2016. They augment the research of Urquhart (2016) by adopting eight tests to investigate the EMH. More specifically, the Ljung-Box test (Ljung and Box 1978), the runs test (Wald and Wolfowitz 1940), the Bartels's test (Bartels 1982) and the wild-bootstrapped automatic variance ratio test (Kim 2009) are adopted. Moreover, the spectral shape tests (Durlauf 1991), the BDS test (Brock et al. 1996), the portmanteau test by Escanciano and Lobato (2009) and the generalized spectral test (Escanciano and Velasco 2006) are performed. The majority of them provide evidence about independence of returns. Thereby, no abnormal profits could be made in the Bitcoin market.

Bariviera (2017) uses daily data that cover the period from 18 August 2011, until 15 February 2017, in order to study long-range dependence of Bitcoin returns and volatility. The methodology employed is the Hurst exponent by using Detrended Fluctuation Analysis (DFA) and overlapping sliding windows. Results provided evidence that during the 2011-2014 period, Bitcoin's returns exhibited persistence but after 2014 there is a tendency towards efficiency. On the contrary, outcomes about Bitcoin's volatility advocate that this has been persistent during the whole period under scrutiny. Moreover, Bariviera et al. (2017) used daily data from 2011 until 2017 and intraday data from 2013 to 2016 concerning prices of Bitcoin and currency values of EUR and GBP, expressed in USD. The Hurst exponent by Detrended Fluctuation Analysis (DFA) in a sliding window is adopted to estimate long-range dependence. Results indicate that values of Hurst exponent alter by significant levels during the early life of Bitcoin, that is until 2014, but takes steps towards stabilization as time passes, as its value moves around 0.5 . It was found that alternative time scales do not significantly affect long-range memory. Moreover, there is evidence that market liquidity does not influence long-term dependence. Furthermore, Kurihara and Fukushima (2017) investigate whether weekly price anomalies exist or not by looking into the market efficiency of Bitcoin. They extract data that cover the period from 17 July 2010 to 29 December 2016 and employ standard ordinary least squares (OLS) and robust least squares (RLS) methodologies. Findings indicate that the Bitcoin market is not characterized by weak-form efficiency. Nevertheless, higher levels of efficiency in the Bitcoin market are revealed as time passes.

The intensely bullish market had taken place in 2017 brought about an increasing volume of academic work investigating the Bitcoin markets. This reflects the increasing interest of academics, investors, speculators and portfolio managers concerning the dominant coin in the cryptocurrency market. As cryptocurrency markets in general are believed to be strongly directed by investor sentiment about Bitcoin, such bibliography casts light on the reasons of investors' decision making.

Alvarez-Ramirez et al. (2018) examine the period June 2013 to June 2017 by applying detrended fluctuation analysis (DFA) over rolling windows to identify long-range correlations for Bitcoin returns. Findings indicate that the Hurst component exhibits cycles and Bitcoin has periods of efficiency but also periods of inefficiency. Asymmetric correlations are found that depend on whether price trends are upwards or downwards, thereby leading to inefficiency due to anti-persistence. By another perspective, Jiang et al. (2018) investigate the existence of long-term dependence in the Bitcoin market in order to provide a clearer picture about the existence or not of efficiency concerning Bitcoin. The data adopted are in a daily frequency and span the period 1 December 2010, to 30 November 2017. The Hurst exponent and a rolling-window approach with a 14-day shift are employed. Furthermore, 
the Ljung-Box test and AVR test are adopted to measure efficiency in the Bitcoin market. Empirical outcomes indicate that this market is not efficient as long-memory is detected and a high value in the inefficiency ratio. Nevertheless, a tendency towards efficiency has been found as time passes. Moreover, Tiwari et al. (2018) adopt daily data from 18 July 2010 to 16 June 2017, in order to employ a battery of tests and examine long-range dependence and informational efficiency of Bitcoin. More specifically, they employ the Detrended Fluctuation Analysis (DFA), the Centered Moving Average- squared absolute fluctuation (CMA-1) and Centered Moving Average-mean absolute fluctuation (CMA-2). Furthermore, they use the Periodogram-Least Squares (Periodogram-LS) and the Periodogram Least Absolute Deviation (Periodogram-LAD). Moreover, the maximum-likelihood estimator (MLE) and the Geweke-Porter-Hudak (GPH) methodologies are employed. Overall, findings reveal that the Bitcoin market is efficient. Nevertheless, outcomes in favor of inefficiency are found regarding the subperiods of April to August 2013 and from August to November 2016. In their paper, Cheah et al. (2018) employ daily closing Bitcoin prices concerning the period 27 November 2011, to 17 March 2017, about the markets in Europe, USA, Australia, Canada and the United Kingdom, in order to study interdependence in a cross-country level. Treatment of cross-market Bitcoin quotes as long-memory procedures by employing a fractionally cointegrated VAR (FCVAR) specification brings about evidence of informational inefficiency across markets. Thereby, long-memory is detected in separate Bitcoin markets as well as in the five-market system. Apart from findings of medium to high inefficiency across Bitcoin markets and long-memory characteristics that permit trading profits, it was found that uncertainty exerts a negative impact on Bitcoin markets. Disequilibrium errors adjust slowly, thereby stochastic shocks could prove really influential for independent Bitcoin markets.

Köchling et al. (2018) used data covering a period before the launch of Bitcoin futures (10 August 2017-10 December 2017) and just after the launch (10 December 2017-10 April 2018) and conducted a number of efficiency tests to investigate the impacts of Bitcoin futures introduction on Bitcoin's efficiency. Seven out of the nine tests employed provide evidence of inefficiency before these futures were initiated. Nevertheless, since the Bitcoin futures started trading, no inefficiency has been detected, so weak-form efficiency has been present. Moreover, no appearance of inefficiency is revealed concerning BitcoinCash, which is a hard fork of Bitcoin. When it comes to Sensoy (2018), he adopted data from 1 January 2013 to 5 March 2015 about tick-by-tick trades in 15, 20, 30, 40 and 45-min frequencies concerning trading volumes and prices of Bitcoin in relation to USD and EUR. Permutation entropy based on Shannon's entropy, a time-varying approach with rolling samples, is employed in order to estimate efficiency. Results indicated that the exchange rates of BTC to USD and to EUR enjoy higher levels of informational efficiency since the beginning of 2016. It should be noted that this amelioration in efficiency exhibits a cyclical pattern as regards the cryptocurrency's value in relation to USD whereas a gradual increase is detected in relation to EUR. Moreover, the former exchange rate is found to be more efficient than the latter. Evidence indicates that higher frequencies lead to lower pricing efficiency. Furthermore, higher liquidity has a positive nexus with informational efficiency while higher volatility presents a negative impact on efficiency in Bitcoin markets.

Among relevant studies is Kristoufek (2018), that investigates the existence of efficiency in two Bitcoin markets regarding the US dollar and the Chinese yuan. He uses data ending July 2017 and starting on 18 July 2010, and 1 February 2014, respectively. The Efficiency Index (EI) developed by Kristoufek and Vosvrda (2013) is employed to measure efficiency. Moreover, the Hurst exponent, the fractal dimension and entropy measures are adopted. Results provide evidence that the USD market is efficient from the middle of 2011 to the middle of 2012. The same is found regarding the period between March and November 2014. Nevertheless, empirical outcomes abide by the conclusion that both the USD and the CNY Bitcoin markets are mostly inefficient during the seven-year period examined. Efficiency is only apparent when Bitcoin quotes render too high and contractionary action in the form of stability is necessary. Moreover, Phillip et al. (2018a) adopted daily data about Bitcoin, Ethereum, Ripple, NEM and Dash from alternative trading platforms until the date of 31 July 2017. They measure generalized long memory (GLM), stochastic volatility (SV), leverage (LVG) and heavy 
tails (HT) by the GLM-SV-LGV-HT model. It is revealed that these highest-capitalized currencies tend to behave similarly regarding their long-memory characteristics as their markets mature. Evidence is found that digital currency markets are not efficient. It should be underlined that long memory, leverage and stochastic volatility characteristics as well as heavy tailedness are detected in all cryptocurrencies under scrutiny. Almudhaf (2018) in his study, looks into the pricing efficiency of Bitcoin Investment Trust (BIT) by employing daily data concerning the closing price and the net asset value (NAV) from 4 May 2015 to 18 November 2016. Ordinary least squares (OLS) methodology with Newey West's (HAC) estimators are utilized. Evidence indicates the existence of a strong and positive nexus between prices and NAV. A powerful and positive linkage between returns of Bitcoin Investment Trust and premiums -in the form of contemporaneous percentage deviations- is detected. The premium is found to be approximately equal to $44 \%$ of the NAV. Outcomes reveal the existence of inefficiency. Therefore, profitable trading strategies could be implemented.

Khuntia and Pattanayak (2018) employ daily Bitcoin data from 18 July 2010 to 21 December 2017 in order to investigate the adaptive market hypothesis $(\mathrm{AMH})$ and the alterations in return predictability in the Bitcoin market. The Dominguez-Lobato (DL) consistent test and generalized spectral (GS) test in a rolling window framework are adopted to test the Martingale Difference Hypothesis (MDH) and detect linear and nonlinear dependence in quotes. Findings reveal the existence of high levels of efficiency from the middle of 2012 until November 2013 as well as since 2015. Nevertheless, inefficiency is found to exist during the subperiods of August 2011-August 2012 and December 2013-December 2014. Thereby, evolving efficiency is verified as periods of efficiency are followed by times of inefficiency and the AMH is valid.

An alternative perspective in examination of efficiency in Bitcoin markets is adopted by Ji et al. (2018). To be more precise, they employ the directed acyclic graph (DAG) methodology along with vector autoregressive (VAR) and error correction model (ECM) schemes as well as the forecast error variance decomposition (FEVD) methodology. They aim to reveal the present and past nexus between Bitcoin and other financial assets, such as equities, bonds, currencies and commodities. The degree of centrality is found to be the lowest concerning the Bitcoin market so its prices cannot be predicted by being based on quotes of other assets. A very small level of inefficiency is detected. Moreover, El Alaoui et al. (2018) investigate the non-linear linkage between alterations in prices and alterations in the trading volume of Bitcoin. They adopt daily data covering the period from 17 July 2010 to 2 May 2018. The methodology they use is the multifractal detrended cross-correlation analysis (MF-DCCA). Empirical findings indicate that non-linear dependency as well as multifractality appear in Bitcoin prices and volume. Anti-persistence is traced in volumes for positive but also for negative values of moments " $q$ ". Thereby, inefficiency is revealed in the Bitcoin market and there are significant opportunities for profitability by traders.

In their work, Vidal-Tomás and Ibañez (2018) employed daily data from 13 September 2011 to 17 December 2017, and from 13 September 2011 to 25 February 2014, concerning the Bitstamp and Mt.Gox markets, respectively. They focused on investigating the existence of semi-strong efficiency in Bitcoin markets, and on how Bitcoin returns were affected by news about this currency and monetary policy events. By adopting Autoregressive Copula Generalized Autoregressive Conditional Heteroskedasticity (AR-CGARCH) and Autoregressive Copula Generalized Autoregressive Conditional Heteroskedasticity in Mean (AR-CGARCH-M) specifications, they provided evidence that while negative events are important for both models, positive news meaningfully affects only Bitstamp and the Bitstamp market is more efficient than Mt.Gox. Furthermore, the Bitcoin market has rendered more efficient as time passes. It should be noted that this digital currency is influenced by its own events, but takes much influence from news about central bank policymaking in an international level. Thereby, higher levels of inefficiency are apparent in response to monetary policy events. Additionally, Al-Yahyaee et al. (2018) conduct a comparison of Bitcoin market's efficiency to markets of alternative assets of primary importance, that is gold, equity and foreign exchange markets. The period under consideration spans 18 July 2010 to 31 October 2017 and daily data are extracted. The methodology they adopt 
in order to estimate efficiency is the multifractal detracted fluctuation analysis (MF-DFA) method that was developed by Kantelhardt et al. (2002) as it is considered to be more flexible than the MF and DFA methodologies. Slopes of Generalized Hurst exponents are employed to represent long-memory characteristics. Empirical outcomes indicate that Bitcoin is the least efficient and with the most time-varying efficiency asset among the markets investigated whereas the equity market is the most efficient one. Notably, Bitcoin has been found to exhibit the largest long-range persistence. Multifractality and long-memory are better detected in small fluctuations and such outcomes could be attributable to lack of confidence by Bitcoin investors. In connection with the study of Urquhart (2017), the academic paper of Mbanga (2018) uses daily volume and closing prices of Bitstamp covering the period from 20 February 2011 to 15 May 2018 to investigate the day-of-week pattern of price clustering in Bitcoin. Findings provide evidence that Bitcoin prices cluster around whole numbers. Additionally, it is found that price clustering does not constitute a phenomenon of Mondays or Fridays, even though evidence shows that it is stronger on Fridays in relation to other days of the week. The most frequent ending decimals of values in Fridays are 0.00, 0.99 and 0.50 . Overall, no evidence is revealing a weekend effect in Bitcoin price clustering.

An econophysics perspective into cryptocurrencies is provided by Lahmiri and Bekiros (2018). They employed daily data of Bitcoin covering the period from 18 July 2010 to 23 October 2017 so as to study the chaos, randomness and multi-scale correlation structure of prices and returns in a low- and a high-regime period. The largest Lyapunov exponent, Shannon entropy, the multi-fractal detrended fluctuation analysis (MF-DFA) and the generalized Hurst exponent are employed for estimations. Evidence advocates the existence of higher uncertainty in returns during the high-price regime period. Multifractality is detected in prices and returns during both periods and this is due to fat-tailed distributions. Furthermore, short alterations in returns dominate in the low regime, whereas long ones during the high regime period. All in all, nonlinear patterns in the Bitcoin market are traced in the high-price level regime. In a somewhat similar vein, Lahmiri et al. (2018) used data in a daily frequency of seven Bitcoin markets so as to study long-range memory of Bitcoin volatility. The methodology employed is the fractionally integrated GARCH (FIGARCH) and the Shannon entropy measure. The analysis takes place under four alternative distributions, that is the Normal, Student- $t$, generalized error (GED) and the t-skewed distributions. Empirical outcomes provide evidence of long-range memory existing no matter which distribution assumption is made. It is found that predictions about volatility can take place based on past information about volatility. BITX presents the lowest level of inefficiency, whereas COINBASE the highest. Overall, there is powerful evidence against the Efficient Market Hypothesis and Bitcoin markets are found to be too risky to serve for hedging.

A number of Japanese authors have also investigated digital currencies. Takaishi (2018) examines the statistical properties of Bitcoin by employing one-minute data from January 2014 to December 2016 and by adopting the multifractal Detrended Fluctuation Analysis (MF-DFA) and Generalized Autoregressive Conditional Heteroskedasticity (GARCH), Glosten-Jagannathan-Runkle Generalized Autoregressive Conditional Heteroskedasticity (GJR-GARCH) and Rational Generalized Autoregressive Conditional Heteroskedasticity (RGARCH) models. Results indicated that Bitcoin prices exhibit multifractality, which comes from temporal correlation as well as the fat-tailed distribution so inefficiency in the Bitcoin market is detected. Moreover, the Brexit decision is found not to have influenced Bitcoin. Takaishi and Adachi (2018) extract data from a one-minute Bitcoin price index (BPI) concerning the period 1 January 2014 to 31 December 2017 as well as one-minute data on EUR-GBP, USD-CHF and USD-JPY exchange rates. Investigation about Taylor effects in Bitcoin time series takes place. Empirical outcomes provide evidence in favor of existence of a Taylor effect. Moreover, it is found that the value of power that renders maximum the autocorrelation of the power of absolute returns is influenced by a time lag in the autocorrelation function. Furthermore, no daily seasonality was detected in the Taylor effect of Bitcoin. This is in contrast to the Taylor impact about currency values in relation to foreign currencies, as they present daily seasonality. Hattori and Ishida (2019) look into how investors conduct arbitrage between Bitcoin spot and futures markets by adopting intraday 
data of CBOE futures price on active contracts and Gemini price from Bloomberg. The data employed cover the period December 2017 to December 2018. They find that arbitrage is sufficient in normal times, whereas market crashed provide opportunities to conduct arbitrage.

There is also a number of recent academic papers concerning efficiency in cryptocurrencies, such as Aggarwal (2019), Bouri et al. (2019), and Zargar and Kumar (2019b). Aggarwal (2019) examines efficiency in Bitcoin markets by employing daily Bitcoin prices about the period from 19 July 2010 until 20 March 2018. In order to do so, he employs serial correlation coefficient tests, unit root tests and the $\mathrm{ARCH}$ test. According to estimation results, Bitcoin returns do not follow a random walk. Thereby, evidence is provided in favor of strong inefficiency in the Bitcoin market. Moreover, tests for non-linear dependence lend support to the claim that high volatility persistence in returns is responsible for such inefficiencies. Furthermore, Bouri et al. (2019) investigated the persistence in the level and volatility of Bitcoin price by also looking for structural break effects. Data was extracted by Bitstamp and covered the period from 19 August 2011 to 29 April 2016. Moreover, data from the Coindesk price index were extracted from the period of 18 July 2010 to 15 December 2015. Parametric and semi-parametric techniques were employed and evidence is in favor of a permanent character of shocks and that there is no mean reversion in levels. Structural alterations are detected in Bitcoin dynamics and at least four structural breaks in each period are traced. Long memory is found both in absolute and squared returns measures of volatility and some occasions of short memory are revealed in the latter case. Overall, evidence towards inefficiency leaves room for trading benefits.

Zargar and Kumar (2019a) adopted data referring to Bitstamp exchange from 21 January 2013 to 8 January 2018. More specifically, 15-, 30-, 60-, 120-min and daily data were employed. They adopted the multiple variance ratio (MVR) test, the automatic variance ratio (AVR) test and the joint variance ratio (JVR) test as well as the Kuan and Lee (KL) test in order to examine whether the martingale hypothesis is valid in the Bitcoin market. Findings provide evidence in favor of informational inefficiency in the Bitcoin market when higher frequencies are employed. This is confirmed by full sample, non-overlapping window and overlapping moving window estimations. Zargar and Kumar (2019b) employ data of the same time period and frequency as Zargar and Kumar (2019a) to investigate the existence of long memory in the Bitcoin market. The Local Whittle estimator (LW), the exact Local Whittle estimator (ELW) and the Autoregressive Moving Average- Fractionally Integrated Asymmetric Power Autoregressive Conditional Heteroskedasticity (ARMA-FIAPARCH) model are employed. Findings indicate statistically significant long-memory parameters that do not fluctuate either for unconditional nor for conditional volatility measures in alternative time scales. Inefficiency is also presented by the examination of "realized" volatilities estimated by LW, ELW and ARFIMA methodologies. Quarterly non-overlapping rolling window estimations also reveal high persistence. Thereby, inefficiency is found to be evident in the Bitcoin market.

\section{Studies about Efficiency in Cryptocurrency Markets in General}

Despite the first-appearing academic papers investigating exclusively Bitcoin, the skyrocketing bullish market of 2017 has led to a number of significant studies concerning alternative digital currencies of high-capitalization. This is because Bitcoin had lost a significant portion of its market share during this boom period owing to investment in alternative digital coins providing a solution to also to lower-budget investors.

Zhang et al. (2018) adopt daily data about Bitcoin, Ethereum, Ripple, Litecoin, Stellar, Dash, Monero and Nem covering the period from 28 April 2013 to 30 April 2018. They employ skewness, kurtosis and Jarque-Bera tests, autocorrelations, GARCH and GJR specifications as well as Detrended Moving Average cross-correlation analysis to discover stylized facts about digital currencies. These methodologies are employed in order to analyze heavy tails, autocorrelations, volatility clustering, leverage impacts, long-range dependence and power-law correlation for these cryptocurrencies. The Hurst exponent combined with rolling windows reveal that the Bitcoin market is moving towards efficiency, as the exponent's value is around 0.5. When it comes to long-range 
dependence of volatility, Bitcoin, Ethereum and Nem present long-range dependence in every period under scrutiny. Moreover, Phillip et al. (2018b) used data of 149 digital currencies with different starting dates but include up to 31 December 2017. They looked into whether long-run autocorrelation exists in the daily-based volatility measures as the very volatile nature of cryptocurrencies can allow. They investigated for jump behavior in volatility. To be more precise, the focus was made on Bitcoin, Ethereum, Ripple, Litecoin, Dash and Monero and they adopt the Jump BAR SV Gegenbauer Log Range (JBAR-SV-GLR) model. Volatility oscillation memory ratios (VOMRs) are employed in order to make out whether currencies have oscillatory features. Results reveal that cryptocurrencies which need more time for transactions such as Bitcoin, exhibit less oscillatory characteristics in comparison with coins like Ripple that are very fast to transact (VOMR $>1)$. It is found that long-run autocorrelations in digital coins should be studied through their volatility dynamics and not by focusing on returns.

Brauneis and Mestel (2018) used daily data covering quotes, dollar volume and market capitalization of 73 digital currencies covering the period of 31 August 2015 to 30 November 2017, in order to look into their efficiency. They employed the Ljung and Box (1978) test for autocorrelation, the runs test (Wald and Wolfowitz 1940), the variance ratio test (Lo and MacKinlay 1988) and the Kim wild-bootstrapped VR test (Chow and Denning 1993). Moreover, the Kim (2009) automatic version of the latter (Choi 1999), the Bartels (1982), the Brock et al. (1996) non-parametric BDS tests as well as the Hurst exponent are employed. Additionally, the non-parametric measure for market efficiency (Godfrey 2017) is adopted. Liquidity is measured by the Amihud (2002) ratio. Results indicated that Bitcoin is the most efficient across cryptocurrencies. It should be noted that the higher is the level of liquidity of a digital currency, the more inefficient this digital coin renders. Thereby, higher liquidity leads to higher capacity of achieving abnormal profits. In their study, Charfeddine and Maouchi (2018) employed daily closing prices of Bitcoin, Ethereum, Ripple and Litecoin covering periods from their launch until February 2018. They investigated long-range dependence (LRD) in returns and volatility of these cryptocurrencies. Empirical outcomes indicate that the LRD behavior (if it exists) in the Bitcoin, Litecoin and Ripple returns series and in the volatility series of Ethereum, is a true behavior, not a statistical artifact. Thereby, evidence indicates that inefficiency exists in the markets of there out of the four digital coins investigated, as Ethereum is the only efficient market.

Wei (2018) collected price and aggregate volume data about 458 cryptocurrencies during the year of 2017. The Amihud (2002) illiquidity ratio was employed in order to measure liquidity and also a series of efficiency tests take place in order to detect signs of autocorrelation and non-independence. Based on the Hurst exponent, evidence revealed anti-persistence in illiquid markets, as the test used values lower than 0.5. Furthermore, smaller currencies were found to go through small boom-bust cycles that depend on the sentiment of speculators. As the digital currencies investigated are separated into five categories depending on their level of liquidity, it can be seen that in more liquid cryptocurrencies, the Hurst exponent takes values close to 0.5 . Thereby, in levels of higher liquidity, prices follow a random walk and markets are more efficient so no abnormal returns by speculation can be achieved. Furthermore, Caporale et al. (2018) employ daily data concerning the four cryptocurrencies with the highest market capitalization (Bitcoin, Litecoin, Ripple, Dash) for the biggest time length possible up to 2017. The methodologies they adopt are the R/S Hurst analysis and fractional integration. Results indicate that the level of persistence is not stable overtime, thereby a large number of fluctuations take place. This is more evident in the case of Litecoin. Findings provide evidence in favor of the Adaptive Market Hypothesis as expressed by Lo (1991) and that higher level of efficiency emerges as time goes by. Litecoin was initially much more inefficient. According to values of the Hurst exponent, it is revealed that Bitcoin, Litecoin and Dash are more efficient, whereas Ripple is not. Overall, the cryptocurrency market is found to be still inefficient, but steps towards efficiency have been realized as the Hurst exponent is decreasing. All in all, opportunities for profitable trading in cryptocurrencies still exist. Bouri et al. (2018) looked into the causality nexus between returns and trading volume of seven major cryptocurrencies (Bitcoin, Ripple, Ethereum, Litecoin, NEM, Dash and Stellar). Daily data was used and the Copula-quantile causality methodology is adopted. Econometric estimations provide 
evidence that trade volume Granger causes extreme negative as well as positive returns on all the seven currencies examined. Nevertheless, findings about impacts on return volatility are weaker. This happens because only the Litecoin, NEM and Dash are found to be recipients of effects and only in low volatility levels. Therefore, no efficiency is detected in cryptocurrency markets in an overall view.

Chaim and Laurini (2018) used a sample of Bitcoin and gold returns as well as USD to EUR exchange rate and the SP500 index concerning the April 2013-May 2018 period. They employ a standard log-normal volatility model and then incorporate the existence of discontinuous jumps to volatility and returns. Markov Chain Monte Carlo (MCMC) procedures are employed for estimations. It was argued that jumps to volatility exhibit a permanent character whereas only contemporaneous impacts exist due to jumps to mean returns. It can be seen that the first volatility period covers from late 2013 to early 2014 and is linked to the Mt.Gox incident. The second period covers 2017 with highest volatility shown in December due to increased public interest. Jumps to mean returns are found to be connected with large and negative price movements due to hacks and forks failed attempts. In a somewhat similar vein, Chaim and Laurini (2019) used data about nine major cryptocurrencies (Bitcoin, Ethereum, Ripple, Litecoin, Stellar, Dash, Monero, Nem, Verge) covering from 16 August 2015 to 31 October 2018. They employed the multivariate non-linear stochastic volatility model proposed by Laurini et al. (2016) for considering common jumps to the mean and volatility of returns. This is based on a Bayesian mechanism that adopts a mixed MCMC procedure. Findings indicate that transitory mean jumps render larger and exhibit higher frequency since early 2017. Simulations revealed that long-memory dependence characteristics are well described by stationary models having jump components.

Kaiser (2018) employed daily data for Bitcoin, BitcoinCash, Cardano, Dash, Ethereum, IOTA, Litecoin, NEO, Ripple and Monero in order to examine seasonality patterns in their returns, volatility, trading volume and a spread estimator. To be more precise, he tested for (i) the Monday effect, (ii) the weekend effect, (iii) the January effect, (iv) the turn-of-the month effect and (v) the Halloween effect. Overall, the EMH in its weak form cannot be rejected. No calendar effect in a consistent and robust level was detected. Nevertheless, Monday and reverse January effects are presented in the Bitcoin market. Moreover, partial significance is found concerning the trading volume, volatility and spreads. In a recent study, Köchling et al. (2019) use data from about 75 cryptocurrencies covering the period from 31 August 2015 until 31 August 2018. Only currencies with capitalization of at least 1 million USD were taken into consideration. They adopt the three delay measures as proposed by Hou and Moskowitz (2005) in order to study time delay of digital currency markets to price information. Outcomes indicated that price delays get significantly lower during the investigated period. It can be seen that cryptocurrency markets render more efficient as time passes. Furthermore, results strongly advocate that there is a powerful nexus of price delay with liquidity and market capitalization.

It should be noted that the majority of studies provide evidence towards the existence of inefficiency in cryptocurrency markets. This lends support to the attractive character of the digital currency markets for investors and particularly for speculators. Market participants can gain insight into future quotes of cryptocurrencies and gain large amounts of profits by studying the determinants of returns and return volatility of Bitcoin and other similar currencies.

\section{Conclusions}

The body of evidence that intends to measure the economic and financial repercussions of the Efficient Market Hypothesis (EMH) on cryptocurrencies has accumulated in an increasing pace. There is already a significant bulk of academic work that provides evidence in favor of inefficiency in digital currency markets and primarily in the Bitcoin market.

Weak-form efficiency that shows whether prices reflect the information contained in the past series of prices has been tested in the great majority of the thirty-eight studies under scrutiny. The largest number of academic papers examined advocate that the EMH does not hold. Long memory in cryptocurrency time series is detected as dependence from past returns is revealed. A battery of tests 
from a wide spectrum are employed such as the Hurst exponent, the Bartels test, the variance ratio test and its specifications among others. Thereby, investors can use past information to predict future returns. This enables speculators to exercise profitable trading strategies suffering only very low risk.

It should be noted that long-range dependence that leads to inefficiency is found to fade out as time passes in the Bitcoin markets as well as in the cryptocurrencies market in general. This provides useful feedback and generates an even more vivid debate about the future of digital currencies. These coins constitute extremely sophisticated investment assets that have attracted an overwhelmingly upcoming number of investors and are expected to become a cornerstone in finance.

The present study fills a gap in relevant literature by providing an overall perspective of the efficiency characteristics and profit opportunities in digital currency markets. Therefore, this systematic survey enlightens policymakers, academics, investors and the economic press about the profitability dynamics inhibited in the markets of these innovative liquidity forms. Avenues for future research include the mapping of the efficiency-measuring dynamics of every methodology adopted in the relevant literature. Moreover, the connection of investor sentiment with the speed of adjustment of cryptocurrency markets towards validity of the Efficient Market Hypothesis should pave the way for new empirical examinations and systematic surveys.

Funding: This research received no external funding.

Conflicts of Interest: The author declares no conflict of interest.

\section{References}

Abdi, Farshid, and Angelo Ranaldo. 2017. A simple estimation of bid-ask spreads from daily close, high, and low prices. The Review of Financial Studies 30: 4437-80. [CrossRef]

Aggarwal, M. Divya. 2019. Do bitcoins follow a random walk model? Research in Economics 73: 15-22. [CrossRef]

Almudhaf, Fahad. 2018. Pricing efficiency of Bitcoin Trusts. Applied Economics Letters 25: 504-8. [CrossRef]

Alvarez-Ramirez, Jose, Eduardo Rodriguez, and Carlos Ibarra-Valdez. 2018. Long-range correlations and asymmetry in the Bitcoin market. Physica A: Statistical Mechanics and Its Applications 492: 948-55. [CrossRef]

Al-Yahyaee, Khamis Hamed, Walid Mensi, and Seong-Min Yoon. 2018. Efficiency, multifractality, and the long-memory property of the Bitcoin market: A comparative analysis with stock, currency, and gold markets. Finance Research Letters 27: 228-34. [CrossRef]

Amihud, Yakov. 2002. Illiquidity and stock returns: cross-section and time-series effects. Journal of Financial Markets 5: 31-56. [CrossRef]

Ammous, Saifedain. 2018. Can cryptocurrencies fulfil the functions of money? The Quarterly Review of Economics and Finance 70: 38-51. [CrossRef]

Bai, Jushan, and Pierre Perron. 2003. Computation and analysis of multiple structural change models. Journal of Applied Econometrics 18: 1-22. [CrossRef]

Baillie, Richard T., Tim Bollerslev, and Hans Ole Mikkelsen. 1996. Fractionally integrated generalized autoregressive conditional heteroskedasticity. Journal of Econometrics 74: 3-30. [CrossRef]

Bariviera, Aurelio F. 2017. The inefficiency of Bitcoin revisited: A dynamic approach. Economics Letters 161: 1-4. [CrossRef]

Bariviera, Aurelio F., María José Basgall, Waldo Hasperué, and Marcelo Naiouf. 2017. Some stylized facts of the Bitcoin market. Physica A: Statistical Mechanics and Its Applications 484: 82-90. [CrossRef]

Bartels, Robert. 1982. The rank version of von Neumann's ratio test for randomness. Journal of the American Statistical Association 77: 40-46. [CrossRef]

Bashan, Amir, Ronny Bartsch, Jan W. Kantelhardt, and Shlomo Havlin. 2008. Comparison of detrending methods for fluctuation analysis. Physica A: Statistical Mechanics and Its Applications 387: 5080-90. [CrossRef]

Baur, Dirk G., Thomas Dimpfl, and Konstantin Kuck. 2018a. Bitcoin, gold and the US dollar-A replication and extension. Finance Research Letters 25: 103-10. [CrossRef]

Baur, Dirk G., Ki Hoon Hong, and Adrian D. Lee. 2018b. Bitcoin: Medium of exchange or speculative assets? Journal of International Financial Markets, Institutions and Money 54: 177-89. [CrossRef] 
Beneki, Christina, Alexandros Koulis, Nikolaos A. Kyriazis, and Stephanos Papadamou. 2019. Investigating volatility transmission and hedging properties between Bitcoin and Ethereum. Research in International Business and Finance 48: 219-27. [CrossRef]

Bollerslev, Tim. 1986. Generalized autoregressive conditional heteroskedasticity. Journal of Econometrics 31: 307-27. [CrossRef]

Bouri, Elie, Naji Jalkh, Peter Molnár, and David Roubaud. 2017a. Bitcoin for energy commodities before and after the December 2013 crash: diversifier, hedge or safe haven? Applied Economics 49: 5063-73. [CrossRef]

Bouri, Elie, Peter Molnár, Georges Azzi, David Roubaud, and Lars Ivar Hagfors. 2017b. On the hedge and safe haven properties of Bitcoin: Is it really more than a diversifier? Finance Research Letters 20: 192-98. [CrossRef]

Bouri, Elie, Chi Keung Marco Lau, Brian Lucey, and David Roubaud. 2018. Trading volume and the predictability of return and volatility in the cryptocurrency market. Finance Research Letters. [CrossRef]

Bouri, Elie, Luis A. Gil-Alana, Rangan Gupta, and David Roubaud. 2019. Modelling long memory volatility in the Bitcoin market: Evidence of persistence and structural breaks. International Journal of Finance E Economics 24: 412-26. [CrossRef]

Brauneis, Alexander, and Roland Mestel. 2018. Price discovery of cryptocurrencies: Bitcoin and beyond. Economics Letters 165: 58-61. [CrossRef]

Brock, W. A., J. A. Scheinkman, W. D. Dechert, and B. LeBaron. 1996. A test for independence based on the correlation dimension. Econometric Reviews 15: 197-235. [CrossRef]

Caporale, Guglielmo Maria, Luis Gil-Alana, and Alex Plastun. 2018. Persistence in the cryptocurrency market. Research in International Business and Finance 46: 141-48. [CrossRef]

Chaim, Pedro, and Márcio P. Laurini. 2018. Volatility and return jumps in bitcoin. Economics Letters 173: 158-63. [CrossRef]

Chaim, Pedro, and Márcio P. Laurini. 2019. Nonlinear dependence in cryptocurrency markets. The North American Journal of Economics and Finance 48: 32-47. [CrossRef]

Charfeddine, Lanouar, and Youcef Maouchi. 2018. Are shocks on the returns and volatility of cryptocurrencies really persistent? Finance Research Letters. [CrossRef]

Cheah, Eng-Tuck, Tapas Mishra, Mamata Parhi, and Zhuang Zhang. 2018. Long memory interdependency and inefficiency in Bitcoin markets. Economics Letters 167: 18-25. [CrossRef]

Chen, Willa W., and Rohit S. Deo. 2006. The variance ratio statistic at large horizons. Econometric Theory 22: 206-34. [CrossRef]

Choi, In. 1999. Testing the random walk hypothesis for real exchange rates. Journal of Applied Econometrics 14: 293-308. [CrossRef]

Chow, K. Victor, and Karen C. Denning. 1993. A simple multiple variance ratio test. Journal of Econometrics 58: 385-401. [CrossRef]

Corbet, Shaen, Andrew Meegan, Charles Larkin, Brian Lucey, and Larisa Yarovaya. 2018. Exploring the dynamic relationships between cryptocurrencies and other financial assets. Economics Letters 165: 28-34. [CrossRef]

Corbet, Shaen, Brian Lucey, Andrew Urquhart, and Larisa Yarovaya. 2019. Cryptocurrencies as a financial asset: A systematic analysis. International Review of Financial Analysis 62: 182-99. [CrossRef]

Dickey, David A., and Wayne A. Fuller. 1979. Distribution of the estimators for autoregressive time series with a unit root. Journal of the American Statistical Association 74: 427-31.

Durlauf, Steven N. 1991. Spectral based testing of the martingale hypothesis. Journal of Econometrics 50: 355-76. [CrossRef]

Dyhrberg, Anne Haubo. 2016a. Bitcoin, gold and the dollar-A GARCH volatility analysis. Finance Research Letters 16: 85-92. [CrossRef]

Dyhrberg, Anne Haubo. 2016b. Hedging capabilities of bitcoin. Is it the virtual gold? Finance Research Letters 16: 139-44. [CrossRef]

El Alaoui, Marwane, Elie Bouri, and David Roubaud. 2018. Bitcoin price-volume: A multifractal cross-correlation approach. Finance Research Letters. [CrossRef]

Engle, R. Fobert. 1982. Autoregressive conditional heteroscedasticity with estimates of the variance of United Kingdom inflation. Econometrica: Journal of the Econometric Society 50: 987-1007. [CrossRef]

Escanciano, J. Carlos, and Carlos Velasco. 2006. Generalized spectral tests for the martingale difference hypothesis. Journal of Econometrics 134: 151-85. [CrossRef] 
Escanciano, J. Carlos, and Ignacio N. Lobato. 2009. An automatic portmanteau test for serial correlation. Journal of Econometrics 151: 140-49. [CrossRef]

Fama, Eugene. F. 1970. Efficient Capital Markets: A Review of Theory and Empirical Work. Journal of Finance 25: 383-417. [CrossRef]

Fry, John, and Eng-Tuck Cheah. 2016. Negative bubbles and shocks in cryptocurrency markets. International Review of Financial Analysis 47: 343-52. [CrossRef]

Geweke, John, and Susan Porter-Hudak. 1983. The estimation and application of long memory time series models. Journal of Time Series Analysis 4: 221-38. [CrossRef]

Giraitis, Liudas, Piotr Kokoszka, Remigijus Leipus, and Gilles Teyssière. 2003. Rescaled variance and related tests for long memory in volatility and levels. Journal of Econometrics 112: 265-94. [CrossRef]

Glosten, Lawrence R., Ravi Jagannathan, and David E. Runkle. 1993. On the relation between the expected value and the volatility of the nominal excess return on stocks. The Journal of Finance 48: 1779-801. [CrossRef]

Godfrey, Keith R. 2017. Toward a model-free measure of market efficiency. Pacific-Basin Finance Journal 44: 97-112. [CrossRef]

Gray, Henry L., Nien-Fan Zhang, and Wayne A. Woodward. 1989. On generalized fractional processes. Journal of Time Series Analysis 10: 233-57. [CrossRef]

Harris, Lawrence. 1991. Stock price clustering and discreteness. The Review of Financial Studies 4: $389-415$. [CrossRef]

Haslett, John, and Adrian E. Raftery. 1989. Space-time modelling with long-memory dependence: Assessing Ireland's wind power resource. Journal of the Royal Statistical Society: Series C (Applied Statistics) 38: 1-21. [CrossRef]

Hattori, Takahiro, and Ryo Ishida. 2019. Do Investors Arbitrage in the Cryptocurrency Market? Evidence from the Bitcoin Futures Market. February 8. Available online: https://ssrn.com/abstract=3209625 (accessed on 30 March 2019). [CrossRef]

He, Ling-Yun, and Shu-Peng Chen. 2011. A new approach to quantify power-law cross-correlation and its application to commodity markets. Physica A: Statistical Mechanics and Its Applications 390: 3806-14. [CrossRef]

Hou, Kewei, and Tobias J. Moskowitz. 2005. Market frictions, price delay, and the cross-section of expected returns. The Review of Financial Studies 18: 981-1020. [CrossRef]

Huber, Peter J. 1964. Robust Estimation of a Location Parameter. The Annals of Mathematical Statistics 35: 73-101. [CrossRef]

Hurst, Harold Ervin. 1951. Long-term storage capacity of reservoirs. Transactions of the American Society of Civil Engineers 116: 770-99.

Ji, Qiang, Elie Bouri, Rangan Gupta, and David Roubaud. 2018. Network causality structures among Bitcoin and other financial assets: A directed acyclic graph approach. The Quarterly Review of Economics and Finance 70: 203-13. [CrossRef]

Jiang, Yonghong, He Nie, and Weihua Ruan. 2018. Time-varying long-term memory in Bitcoin market. Finance Research Letters 25: 280-84. [CrossRef]

Johansen, Søren, and Morten Ørregaard Nielsen. 2012. Likelihood inference for a fractionally cointegrated vector autoregressive model. Econometrica 80: 2667-732. [CrossRef]

Kaiser, Lars. 2018. Seasonality in cryptocurrencies. Finance Research Letters. [CrossRef]

Kantelhardt, Jan W., S. A. Zschiegner, Eva Koscielny-Bunde, Shlomo Havlin, Armin Bunde, and H. Eugene Stanley. 2002. Multifractal detrended fluctuation analysis of nonstationary time series. Physica A: Statistical Mechanics and its Applications 316: 87-114. [CrossRef]

Katsiampa, Paraskevi. 2017. Volatility estimation for Bitcoin: A comparison of GARCH models. Economics Letters 158: 3-6. [CrossRef]

Khuntia, Sashikanta, and J. K. Pattanayak. 2018. Adaptive market hypothesis and evolving predictability of bitcoin. Economics Letters 167: 26-28. [CrossRef]

Kim, Jae H. 2009. Automatic variance ratio test under conditional heteroskedasticity. Finance Research Letters 6: 179-85. [CrossRef]

Köchling, Gerrit, Janis Müller, and Peter N. Posch. 2018. Does the introduction of futures improve the efficiency of Bitcoin? Finance Research Letters. [CrossRef]

Köchling, Gerrit, Janis Müller, and Peter N. Posch. 2019. Price delay and market frictions in cryptocurrency markets. Economics Letters 174: 39-41. [CrossRef] 
Kristoufek, Ladislav. 2018. On Bitcoin markets (in) efficiency and its evolution. Physica A: Statistical Mechanics and its Applications 503: 257-62. [CrossRef]

Kristoufek, Ladislav, and Miloslav Vosvrda. 2013. Measuring capital market efficiency: Global and local correlations structure. Physica A: Statistical Mechanics and its Applications 392: 184-93. [CrossRef]

Kuan, Chung-Ming, and Wei-Ming Lee. 2004. A new test of the martingale difference hypothesis. Studies in Nonlinear Dynamics \& Econometrics 8: 1-26.

Kurihara, Yutaka, and Akio Fukushima. 2017. The market efficiency of Bitcoin: A weekly anomaly perspective. Journal of Applied Finance and Banking 7: 57-64.

Kwiatkowski, Denis, Peter C. Phillips, Peter Schmidt, and Yongcheol Shin. 1992. Testing the null hypothesis of stationarity against the alternative of a unit root: How sure are we that economic time series have a unit root? Journal of econometrics 54: 159-78. [CrossRef]

Lahmiri, Selim, and Stelios Bekiros. 2018. Chaos, randomness and multi-fractality in Bitcoin market. Chaos, Solitons $\mathcal{E}$ Fractals 106: 28-34.

Lahmiri, Salim, Stelios Bekiros, and Antonio Salvi. 2018. Long-range memory, distributional variation and randomness of bitcoin volatility. Chaos, Solitons \& Fractals 107: 43-48.

Laurini, Márcio Poletti, Mauad, Roberto Baltieri, and Fernando Antonio Aiube. 2016. Multivariate Stochastic Volatility-Double Jump Model: An application for oil assets. Banco Central do Brasil, Working Papers, 415. Brasília, Brazil: Central Bank of Brazil.

Lee, Tae-Hwy, and Weiping Yang. 2014. Granger-causality in quantiles between financial markets: Using copula approach. International Review of Financial Analysis 33: 70-78. [CrossRef]

Ljung, Greta M., and George E. Box. 1978. On a measure of lack of fit in time series models. Biometrika 65: 297-303. [CrossRef]

Lo, Andrew W. 1991. Long-Term Memory in Stock Market Prices. Econometrica 59: 1279-313. [CrossRef]

Lo, Andrew W., and A. Craig MacKinlay. 1988. Stock market prices do not follow random walks: Evidence from a simple specification test. The Review of Financial Studies 1: 41-66. [CrossRef]

López, Fernando, Mariano Matilla-García, Jesús Mur, and Manuel Ruiz Marín. 2010. A non-parametric spatial independence test using symbolic entropy. Regional Science and Urban Economics 40: 106-15. [CrossRef]

Massey, Frank J., Jr. 1951. The Kolmogorov-Smirnov test for goodness of fit. Journal of the American Statistical Association 46: 68-78. [CrossRef]

Matilla-García, Mariano, and Manuel Ruiz Marín. 2008. A non-parametric independence test using permutation entropy. Journal of Econometrics 144: 139-55. [CrossRef]

Mbanga, Cedric L. 2018. The day-of-the-week pattern of price clustering in bitcoin. Applied Economics Letters 1-5. [CrossRef]

Nadarajah, Saralees, and Jeffrey Chu. 2017. On the inefficiency of Bitcoin. Economics Letters 150: 6-9. [CrossRef]

Nakamoto, Satoshi. 2008. Bitcoin: A Peer-to-Peer Electronic Cash System. Cambridge: MIT Press.

Nelson, Daniel B. 1991. Conditional heteroskedasticity in asset returns: A new approach. Econometrica: Journal of the Econometric Society 59: 347-70. [CrossRef]

Peng, C. K., Shlomo Havlin, H. Eugene Stanley, and Ary L. Goldberger. 1995. Quantification of scaling exponents and crossover phenomena in nonstationary heartbeat time series. Chaos: An Interdisciplinary Journal of Nonlinear Science 5: 82-87. [CrossRef] [PubMed]

Phillip, Andrew, Jennifer S. Chan, and Shelton Peiris. 2018a. A new look at Cryptocurrencies. Economics Letters 163: 6-9. [CrossRef]

Phillip, Andrew, Jennifer S. Chan, and Shelton Peiris. 2018b. On long memory effects in the volatility measure of Cryptocurrencies. Finance Research Letters 28. [CrossRef]

Phillips, Peter C. 1987. Time series regression with a unit root. Econometrica: Journal of the Econometric Society 55: 277-301. [CrossRef]

Robinson, Peter M. 1995a. Gaussian semiparametric estimation of long range dependence. The Annals of Statistics 23: 1630-61. [CrossRef]

Robinson, Peter M. 1995b. Log-periodogram regression of time series with long range dependence. The Annals of Statstics 23: 1048-72. [CrossRef]

Rogers, L. Chris G., and Steven E. Satchell. 1991. Estimating variance from high, low and closing prices. The Annals of Applied Probability 1: 504-12. [CrossRef]

Selgin, George. 2015. Synthetic commodity money. Journal of Financial Stability 17: 92-99. [CrossRef] 
Sensoy, Ahmet. 2018. The inefficiency of Bitcoin revisited: A high-frequency analysis with alternative currencies. Finance Research Letters. [CrossRef]

Shannon, Claude E. 1948. A note on the concept of entropy. Bell System Technical Journal 27: 379-423. [CrossRef]

Shimotsu, Katsumi, and Peter C. Phillips. 2005. Exact local Whittle estimation of fractional integration. The Annals of Statistics 33: 1890-933. [CrossRef]

Spirtes, Peter, Clark N. Glymour, Richard Scheines, David Heckerman, Christopher Meek, Gregory Cooper, and Thomas Richardson. 2000. Causation, Prediction, and Search. Cambridge: MIT Press.

Takaishi, T. 2018. Statistical properties and multifractality of Bitcoin. Physica A: Statistical Mechanics and Its Applications 506: 507-19. [CrossRef]

Takaishi, Tetsuya, and Takanori Adachi. 2018. Taylor effect in Bitcoin time series. Economics Letters 172: 5-7. [CrossRef]

Taqqu, Murad S., Vadim Teverovsky, and Walter Willinger. 1995. Estimators for long-range dependence: An empirical study. Fractals 3: 785-98. [CrossRef]

Taylor, Stephen J. 2007. Modelling Financial Time Series. Hackensack: World Scientific Publishing Co. Pte. Ltd.

Tiwari, Aviral Kumar, R. K. Jana, Debojyoti Das, and David Roubaud. 2018. Informational efficiency of Bitcoin-An extension. Economics Letters 163: 106-9. [CrossRef]

Urquhart, Andrew. 2016. The inefficiency of Bitcoin. Economics Letters 148: 80-82. [CrossRef]

Urquhart, Andrew. 2017. Price clustering in Bitcoin. Economics letters 159: 145-48. [CrossRef]

Vidal-Tomás, David, and Ana Ibañez. 2018. Semi-strong efficiency of Bitcoin. Finance Research Letters 27: 259-65. [CrossRef]

Wald, Abraham, and Jacob Wolfowitz. 1940. On a test whether two samples are from the same population. The Annals of Mathematical Statistics 11: 147-62. [CrossRef]

Wei, Wang Chun. 2018. Liquidity and market efficiency in cryptocurrencies. Economics Letters 168: 21-24. [CrossRef]

Zakoian, Jean-Michel. 1994. Threshold heteroskedastic models. Journal of Economic Dynamics and control 18: 931-55. [CrossRef]

Zargar, Faisal Nazir, and Dilip Kumar. 2019a. Informational inefficiency of Bitcoin: A study based on high-frequency data. Research in International Business and Finance 47: 344-53. [CrossRef]

Zargar, Faisal Nazir, and Dilip Kumar. 2019b. Long range dependence in the Bitcoin market: A study based on high-frequency data. Physica A: Statistical Mechanics and Its Applications 515: 625-40. [CrossRef]

Zhang, Wei, Pengfei Wang, Xiao Li, and Dehua Shen. 2018. The inefficiency of cryptocurrency and its cross-correlation with Dow Jones Industrial Average. Physica A: Statistical Mechanics and Its Applications 510: 658-70. [CrossRef]

Zhou, Wei-Xing. 2008. Multifractal detrended cross-correlation analysis for two nonstationary signals. Physical Review E 77: 066211. [CrossRef] [PubMed]

Zhu, Ke, Philip L. Yu, and Wai Keung Li. 2014. Testing for the buffered autoregressive processes. Statistica Sinica 24: 971-84. [CrossRef]

Zivot, Eric, and Donald W. K. Andrews. 2002. Further evidence on the great crash, the oil-price shock, and the unit-root hypothesis. Journal of Business \& Economic Statistics 20: 25-44.

(C) 2019 by the author. Licensee MDPI, Basel, Switzerland. This article is an open access article distributed under the terms and conditions of the Creative Commons Attribution (CC BY) license (http://creativecommons.org/licenses/by/4.0/). 